\title{
Development of Consolidated Sarawak Geotechnical Site Investigation for Sarawak Soil
}

\author{
Norazzlina M. Sa'don ${ }^{1}$, Abdul Razak Abdul Karim', Bong Chih How $^{2}$, Linda \\ Wong Lin Juan' ${ }^{2}$, Louisa Dubah Anak Hubert Chunggat ${ }^{1}$
}

${ }^{1}$ Faculty of Engineering,

Universiti Malaysia Sarawak, 94300 Kota Samarahan, Sarawak, MALAYSIA

${ }^{2}$ Faculty of Computer Science and Information Technology,

Universiti Malaysia Sarawak, 94300 Kota Samarahan, Sarawak, MALAYSIA

*Corresponding Author

DOI: https://doi.org/10.30880/ijie.2020.12.09.020

Received 27 August 2020; Accepted 24 November 2020; Available online 30 December 2020

\begin{abstract}
The development of spatial or non-spatial digitized Consolidated Sarawak Geotechnical Site Investigation (CoGSI) database aims to enable information to be stored in a digital form with the efficient search and fast retrieving data. The CoGSI database for Sarawak Soil is a function of a database management system, which consists of the site information; includes the project name, locations coordinates (division), borehole logs, field and laboratory test results. The main objectives of the project are to collect, store \& digitized all verified \& approved Geotechnical SI data and the input gathered from the local authority, consultants and contractors. The digitized database would be enormous value for future planning of infrastructure developments; making preliminary design estimates for earthwork/foundation assessment; and future decision making with early identification of potential areas for construction purposes, which will produce an economic and safe design. The SI databases are important resources where the insufficient ground conditions information, will cause either a significantly over-designed or an under-designed solution, which lead to potential failures. In addition, the project is also intended to realize a web-based application to allow users to search borehole, view bore-logs and provides digital downloadable boreholes data of the available ground information in a standard format for analysis. At present most of the SI data are available in the form of hardcopy reports, which is time consuming and often frustrating, especially when the required report or data cannot be found. In summary, the Consolidated Sarawak Geotechnical Site Investigation (CoGSI) database system, which stored in a digital format are deployed as a webbased system. This platform provides exploration of the digital databases, which then can be accessed anywhere and anytime through the desktop \& portable computer and smart phones with internet access facility.
\end{abstract}

Keywords: Database management, site investigation, digital web-based, construction

\section{Introduction}

The geotechnical site investigation (SI) is routinely performed to the commencement of any projects prior to the decent design and cost-effective construction for all civil engineering and building construction works. The geotechnical engineers will be interpreting the subsurface conditions based on the SI report for planning, design and monitoring of the designated project. It is also help to overcome any possible difficulties, delays that may arise during construction period, disputes, claims and project cost overruns due to ground and other local conditions [1], [2]. 